\title{
Mitigating the Steel Structures Using Friction Damper Device
}

\author{
Dawood M. ${ }^{1}$, El-Hakem Y. ${ }^{2}$, Tork B. ${ }^{3}$, Mokhtar A. ${ }^{4}$ \\ ${ }^{1}$ (Structural Engineering, Ain Shams University, Egypt) \\ ${ }_{2}^{2}$ (Dynamics of Structures, National Water Research Center, Egypt) \\ ${ }^{3}$ (Structural Engineering, Ain Shams University, Egypt) \\ ${ }^{4}$ (Structural Engineering, Ain Shams University, Egypt)
}

\begin{abstract}
This paper presents an experimental work on a friction damper locally manufactured in Egypt. The device idea is based on well-known devices that convert the kinetic energy to heat energy and transform destructive energy into harmless oscillations. It is manufactured from cheap materials in the local market in Egypt. The tests are performed at the construction institute of National Water Research Center in Egypt. Such damping device is equipped to a steel frame and its properties and efficiency are investigated under shaking table excitation. The obtained results from the current work prove that the manufactured device has performed very well although it is made from cheap materials. The damper reduces the frame response by $83 \%$ and its damping capacity is stable over 100 loading cycles. Mathematical modeling for the damper is verified and consequently, a change in the damper equipping configuration to the frame is proposed and studied analytically.
\end{abstract}

Keywords: damping ratio, experimental test, finite element, friction damper, natural frequency

\section{Introduction}

The traditional techniques used for increasing the structure's lateral resistance against dynamic loads like wind, waves, earthquake, blast and etc. are ineffective and very expensive. Therefore, another technology has been innovated in the 1970s named "Smart Structures". Smart structure technology depends on both structure's own strength and additional dynamic energy dissipation devices. Many researches and developments have appeared until today in this field.Energy dissipation control systems are classified into two general types, active and passive. The second type is widely used for structures. One of the passive control devices is the friction damper which shall be focused on in this paper. Friction damper devices can be considered very efficient in dissipating the dynamic energy with low cost. Pall and Marsh [1] introduced passive friction dampers based on the model of friction brakes. Their behavior has been studied analytically and experimentally. Aiken et al. [2,3] discussed a friction damper mounted on K-bracing. When the structure excites, relative movement between the structure and the brace drives a copper alloy friction pad as it slides along the inner surface of a cylinder's steel casing. Resistant force is produced through the action of a spring against inner and outer wedges. Nims et al. [4] developed a more sophisticated energy-dissipating-restraint device that dissipates energy on the interface between bronze friction wedges and a steel cylinder wall. The combination of wedges, stops, and inner springs produce friction proportional to the displacement of the device's edges. Fitzgerald et al. [5] proposed a friction damper that utilizes slotted bolted connections in concentrically braced frames. Extensive studies have been conducted on friction dampers, which has led to their practical application for structural seismic protection [2, 6]. Mualla [7] innovated a Friction Damper Device (FDD), based on friction between steel plates and friction pad made from special material. The steel plates are rotating around each other giving large displacement demand. Experimental work has been performed for the damper using displacement and force frequency control which proved that the FDD is displacement-dependent type. The friction damped frames were simulated by various finite element software and many trials were performed to consider its rotations against seismic loads. Mualla and Belev [8] introduced numerical analysis for the FDD seismic response. Amir et al. [9] studied the influence of friction damper device on the performance of steel moment frames. They performed an analytical study for three frames with 3,7 and 12 stories equipped with FDD; they investigated the friction damper capability in reducing frame responses. Nikam et al. [10] discussed the advantages of using friction dampers in dissipating seismic energy for the buildings and summarized the construction and maintenance aspects.

In this paper, an investigation is performed based on the idea of the friction damper device innovated by Mualla [7]. This device is locally manufactured with different friction material and tested in the construction institute of National Water Research Center (NWRC) in Egypt as detailed in this paper. Then, an FEM for the friction device is simulated. The output results of the frame with damper are compared with the experimental results to verify the methodology used in the FEM. First the friction damper is equipped over chevron bracing. Then a new configuration is proposed for the damping device to be installed without bracing. This proposed configuration is studied analytically using FEM. 


\section{Friction Damper Device Used In This Work}

The friction damper device is composed from three steel plates, pre-stressed bolt, nut, spring washers, hard washers and filling friction pad disks made from Teflon. The device is fabricated and assembled as shown in Fig. 1.The steel plates and Teflon friction disks are held together with proper tightening force using the prestressed bolt. The purpose from the spring washers is to avoid any relief in bolt tightening force during the dynamic loading. While the hard washers distribute the stresses applied on the side plates from the spring washers. The central plate is connected with the frame girder, and the two side plates are linked with chevron bracing made from pre-stressed tie rods as shown in Fig. 2.

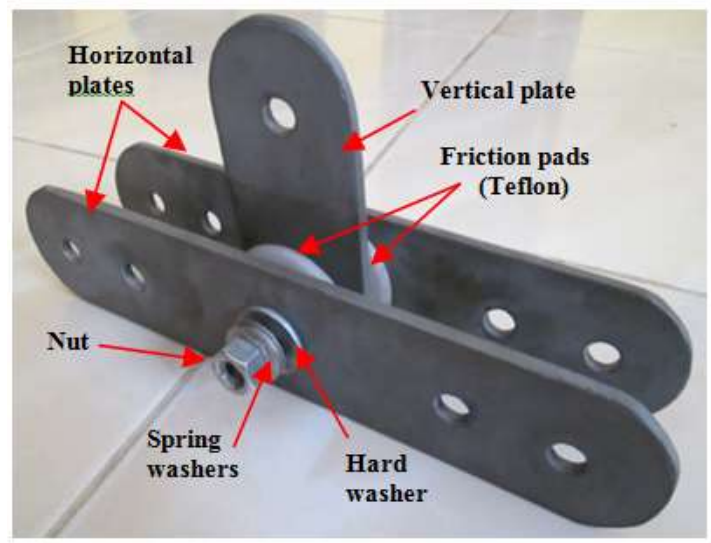

Fig. 1: FDD components

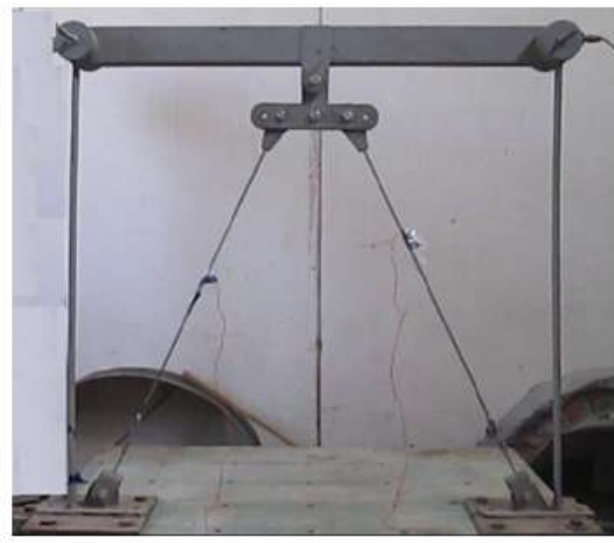

Fig. 2: Tested frame with damper

When a base excitation takes place under a frame structure, lateral forces are created at frame girder. The resulting lateral displacements produce moment about FDD which is resisted by the friction forces created between friction disks and steel plates. Such friction forces dissipate kinetic energy from the structure.

\section{Tested Model Description And Test Program Summary}

Here the tested frame is one bay frame; its overall dimensions are $1125 \mathrm{~mm}$ high and $1100 \mathrm{~mm}$ span. The frame legs are steel bars with 50x5 mm rectangular section. The frame girder is 90x50x3 mm box steel section and is welded to the frame legs by all-around full penetration weld. Frame column bases are fixed on shaking table by four bolts $14 \mathrm{~mm}$ diameter for each. The shaking table is a unidirectional type and has dimensions of $1.25 \times 1.25 \mathrm{~m}$. Its maximum excitation frequency is $4.29 \mathrm{~Hz}$. This frame has been examined with and without the FDD to compare the results. The force-deflection hysteretic relation is extracted for the damper itself; and, the frame overall response is measured. By comparing the frame response behaviour with and without the friction damper device, it is shown that the damper reduces $83 \%$ from the frame response. In order to confirm the accuracy of the measuring devices, tests are executed and organized for the frame without the FDD and compared with FEM. Then, the damper is simulated in the FEM using bilinear relation and the results compared with the experimental output.

\section{Experimental Setup}

This frame is loaded by applying $12 \mathrm{Kg}$ of metal wheels equally distributed in both frame girder ends. In order to measure the frame response regarding the applied frequencies, the following measuring devices are used; (1) two dynamic LVDTs are used to measure the displacements; the first is attached to frame girder and the second is fixed to frame girder and attached to the FDD; (2) two accelerometers: the first is side mounted to the frame girder and the second is side mounted to the shaking table. The accelerations for both shaking table and frame are measured by accelerometers and the frame drift and FDD displacement are measured using the dynamic LVDT. The used accelerometer is piezoelectronic type. Its model is PCB, No. 080A54. Line powered signal conditioners are provided to supply constant current excitation to the accelerometers. Dynamic LVDT is composed of two parts, a tube and a sliding rod. The displacement can be determined throughout the magnetic field transmitted between both the tube and the sliding rod. The accelerometers and LVDT transfer signals to a data acquisition system. This system controls the measuring process and converts the analog signals to digital. Also, the data is stored on a computer for further analysis. The type of data acquisition card is PCD-320A with built-in software that is produced by KYOWA. This software is used to manage the measurements from all channels. Devices' instrumentation setup and the configuration of measurement system are shown in Fig. 3. 


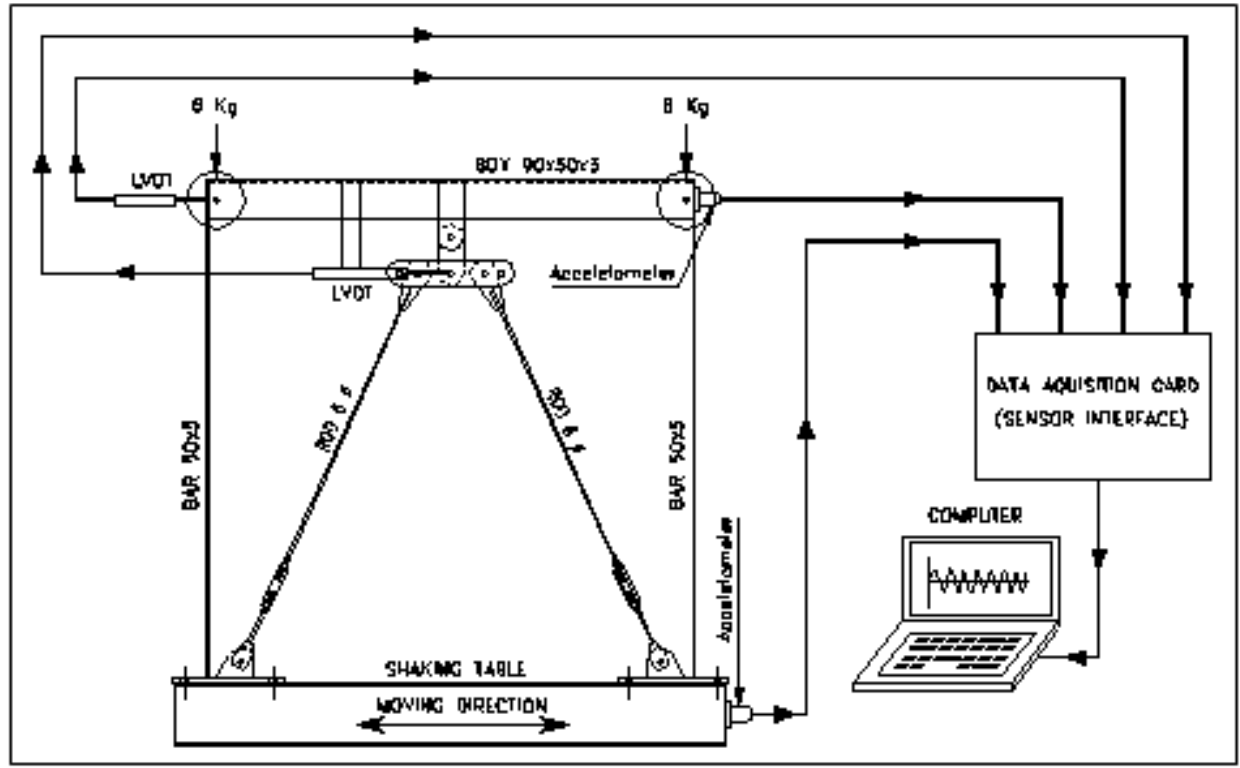

Fig.3: Test Setup

\section{Validation Test And Data Analysis}

As mentioned before, verification for the measuring devices is performed by testing the frame without the friction damper and comparing the results with the FEM. The frame is subjected to three steady state excitation tests with different frequencies. The shaking table frequencies, sampling recording frequency rates, sampling time and cut off frequencies are as illustrated in Table (1). It is important to highlight that the values of sampling frequency rates and cut off frequencies are chosen to get proper accuracy for the results and to avoid errors. The acceleration records are recorded from several sampling rates starting from $100 \mathrm{~Hz}$ to $1000 \mathrm{~Hz}$. Then, a double integration process is applied. The displacements are compared with the LVDT results. The 200 $\mathrm{Hz}$ sampling rate is found to give reliable results. The displacement graphs obtained from double integration has base line error. It is corrected by filtering the low frequencies [11]. The minimum cut off frequency value of 0.4 is chosen for this purpose. While the maximum cut off values are chosen by judgment incrementally with observing the smoothness of the acceleration curves.

Table 1. Dynamic experimental data used in the test

\begin{tabular}{|c|c|c|c|c|}
\hline $\begin{array}{l}\text { Test } \\
\text { No. }\end{array}$ & $\begin{array}{ll}\text { Shaking } & \text { table } \\
\text { frequency }(\mathrm{Hz})\end{array}$ & $\begin{array}{l}\text { Sampling } \\
\text { time (sec.) }\end{array}$ & $\begin{array}{l}\text { Sampling recording } \\
\text { frequency rate }(\mathrm{Hz})\end{array}$ & Cut off frequency $(\mathrm{Hz})$ \\
\hline \multirow{2}{*}{1} & \multirow{2}{*}{0.714} & \multirow{2}{*}{40} & \multirow{2}{*}{200} & Band pass, 0.4 to $40 \mathrm{~Hz}$ (for table) \\
\hline & & & & Band pass, 0.4 to $13 \mathrm{~Hz}$ (for frame) \\
\hline \multirow{2}{*}{2} & \multirow{2}{*}{1.0} & \multirow{2}{*}{40} & \multirow{2}{*}{200} & Band pass, 0.4 to $40 \mathrm{~Hz}$ (for table) \\
\hline & & & & Band pass, 0.4 to $13 \mathrm{~Hz}$ (for frame) \\
\hline \multirow{2}{*}{3} & \multirow{2}{*}{1.43} & \multirow{2}{*}{40} & \multirow{2}{*}{200} & Band pass, 0.4 to $40 \mathrm{~Hz}$ (for table) \\
\hline & & & & Band pass, 0.4 to $13 \mathrm{~Hz}$ (for frame) \\
\hline
\end{tabular}

The acceleration and displacement signals are collected as raw records. The software "seismosignal" version 4.3.0 is used to filter and analyze the recorded data. Accordingly, the natural period and the damping ratio are extracted from the output data. The frame dynamic characteristics are obtained from the FRF for the frame response. The FRF avoids the input frequencies' effect measured by accelerometer attached to the shaking table. The FRF can be calculated by dividing the output FFT to the input FFT [12] as given in equation (5.1).

$$
\mathrm{H}_{(\mathrm{c})}=\frac{\mathrm{X}_{(\mathrm{c})}}{\mathrm{F}_{(\mathrm{c})}}
$$

The FFT is an algorithm that converts the signal from time domain to a representation frequency domain and vice versa. It has been generated using seismosignal software. Butterworth filtering has also been done to remove the frequency noises in both input and output signals by the cut off values mentioned in Table 1 . The peak of the FRF plot corresponds to the natural mode of the system with the frequency at which this peak occurs being the natural frequency. Fig. 4 shows the resulting FRF for test no. 1 as an example.

The obtained natural frequencies for tests 1, 2 and 3 are 1.68457, 1.68457 and $1.66016 \mathrm{~Hz}$ respectively. The damping ratio is calculated from the FRF plot by the half power bandwidth method [12]. The damping ratio can be computed by Equation (5.2). 


$$
\xi=\frac{f_{B}-f_{A}}{2 f_{F}}
$$

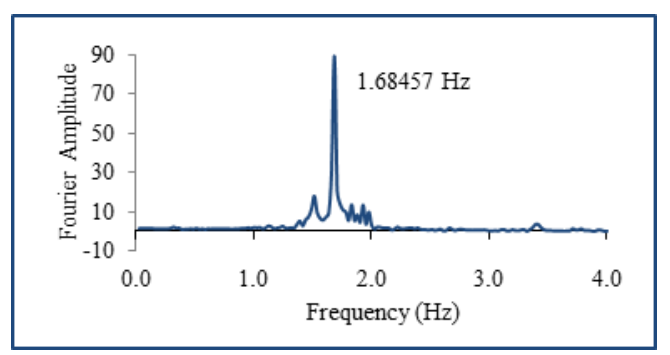

Fig. 4: FRF for Test No.1

The damping ratios for the three tests obtained using the half power bandwidth method are summarized in Table 2. It is observed that the variation in natural frequencies and damping ratio obtained from the FRF method within $3 \%$, which represent confidence in this method.

Table 3. Dynamic Parameters from FRF

\begin{tabular}{|l|c|c|c|}
\hline \multicolumn{1}{|c|}{ Experimental test } & Test 1 & Test 2 & Test 3 \\
\hline Response $/ \sqrt{\mathbf{2}}$ & 63.15757 & 78.66471 & 138.7682 \\
\hline $\mathrm{fA}(\mathrm{Hz})$ & 1.67286 & 1.67457 & 1.65286 \\
\hline $\mathrm{fB}(\mathrm{Hz})$ & 1.69629 & 1.69571 & 1.67543 \\
\hline $\mathrm{fr}(\mathrm{Hz})$ & 1.68457 & 1.68457 & 1.66016 \\
\hline$\xi(\%)$ & 0.695 & 0.627 & 0.680 \\
\hline
\end{tabular}

\section{Experimental Evaluation Of The Damping System}

As illustrated in section 4, the FDD is added to the frame as illustrated in Fig. 2. The evaluation of damping system is performed for two items. The first is performed for the damper device and the second for the overall frame behavior after adding the FDD to the frame structure. The FDD is tested to extract the hysteresis relation between acting forces and displacements. This test is executed by fixing an LVDT to the frame girder and attaching its rod to damper center as shown in Fig. 3, which allows getting the displacement of the FDD separately. On the other hand, the accelerometer is attached to the frame girder to measure the acting acceleration on the FDD. The shaking table is excited for constant harmonic motion with frequency $1.43 \mathrm{~Hz}$ through 40 seconds. The recoded acceleration, displacement and extracted hysteresis curve are shown in Fig. 5. Such hysteresis show almost stable behavior for the FDD with the used Teflon material as a friction pad between the steel plates at the tightening point. Damper stability is examined through around 100 cycles, which gives the confidence for device durability through seismic or any occasionally dynamic loading time. In addition, the frame responses with and without the FDD are recorded and compared. Fig. 6 demonstrates a very good and efficient behavior for the damping system in reducing the frame drift. The maximum displacement is reduced from $60 \mathrm{~mm}$ to $10 \mathrm{~mm}$, which represents $83 \%$ difference. The frame natural frequency is shifted from $1.66 \mathrm{~Hz}$ to $23.93 \mathrm{~Hz}$.

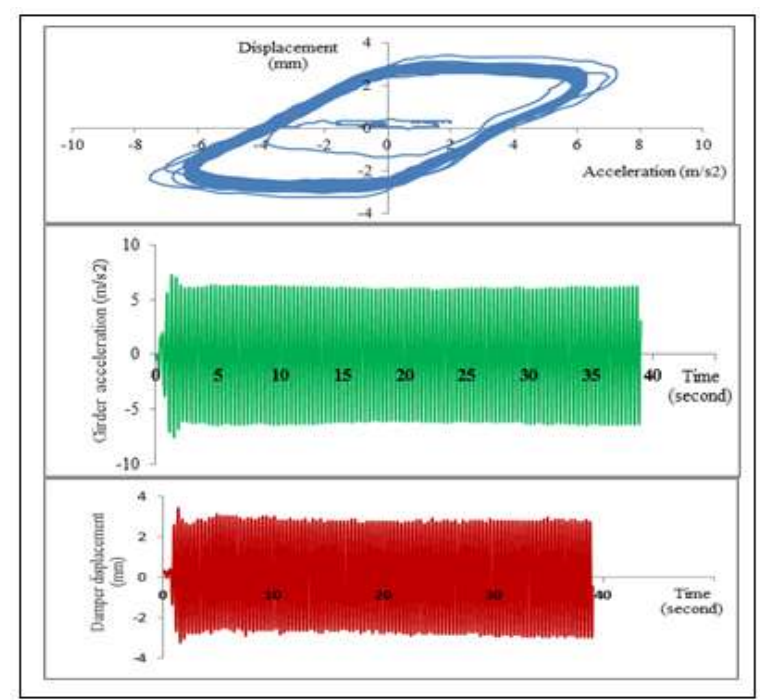

Fig. 5: Experimental displacement cycle test of friction damper 


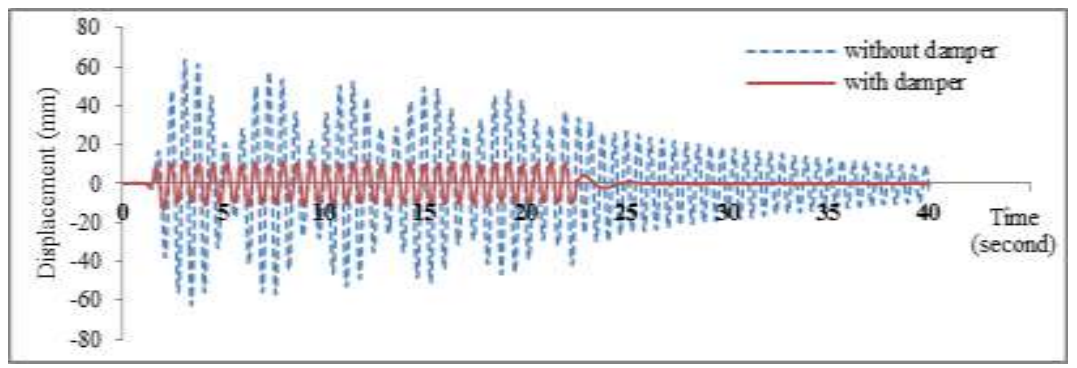

Fig. 6: Basic frame response with and without FDDs

These results indicate that this technology is an alternative for absorbing dynamic energy with a simple method. The damper hysteresis behavior gives the advantage of its ability to dissipate large amount of the external dynamic energy. Furthermore, the device is easy and flexible to be added to structures either new or for rehabilitation purposes. In addition, its maintenance after heavy dynamic loads is easy if needed.

\section{FE Modeling Without Friction Damper}

The purpose of this model is to validate the accuracy of the measuring devices compared with the FEM frame behaviour. The frame is built using SAP 2000 software package version 14.2.2. Frame members are modelled using frame elements. The weights mounted on the frame are assigned as masses in X-direction. The damping ratio defined in the model is $0.667 \%$. This is the average of tests 1 to 3 . The defined steel material properties are $2.4 \mathrm{t} / \mathrm{cm}^{2}, 2100 \mathrm{t} / \mathrm{cm}^{2}, 810 \mathrm{t} / \mathrm{cm}^{2}$ and $7.85 \mathrm{t} / \mathrm{m}^{3}$ for yield stress, Young's modulus, shear modulus and material density, respectively. Yield stress is taken from the workshop manufacturer. The other material properties are the nominal values mentioned in the Egyptian code of steel structures [13]. A modal analysis is executed. The natural frequency from the FEM is $1.48548 \mathrm{~Hz}$. This value represents around $13 \%$ difference compared with the experimental result. Many researches compare experimental and FEM results. The variation is between 10 to 22\%, (see for example: Sivaraoset al. [14], 10\%;Velmuruganet al. [15], 20\%;Rahmanet al. [16], 22\%). Hence, the deviation occurring in the current model can be acceptable.

It can be observed that the natural frequency calculated by the FEM is lower than that obtained from the experimental test, which means that the computer model is more flexible than the real case. This result is logic because the beam-column connection is modelled in the program as a node, while the real connection is a surface with the beam depth. A more accurate model is executed by simulating the steel frame members using shell elements; then, the frame is reanalyzed with the same loads and boundary conditions. Three mesh sizes are used for both frame girder and legs. First; each box girder side and legs are modelled with one shell element, second; the girder sides are $60 \times 45 \mathrm{~mm}$ and legs are $60 \times 25 \mathrm{~mm}$, third; the girder sides are $30 \times 22.5 \mathrm{~mm}$ and legs are $30 \times 25 \mathrm{~mm}$. The obtained natural frequencies from these models are 1.649, 1.641 and $1.644 \mathrm{~Hz}$, respectively. These results are very close to the experimental results. It is worth mentioning that considering the P- $\Delta$ effect is taken in the analysis. The input excitation records applied by the shaking table are assigned to the finite element model as a time history function. The input function is a relation between acceleration and time. In tests no.1, 2 and 3 the frame drifts time history results for both finite element analysis and experimental tests are compared and show good agreement. The difference in the maximum displacement values are $3.6 \%, 2.1 \%$ and $2.8 \%$ for tests no.1, 2 and 3, respectively. Fig. 7-a and 7-b show frame deformation shapes in lab and FEM, respectively. Fig. 8 shows a comparison between experimental and FEM response results for test no. 3 .

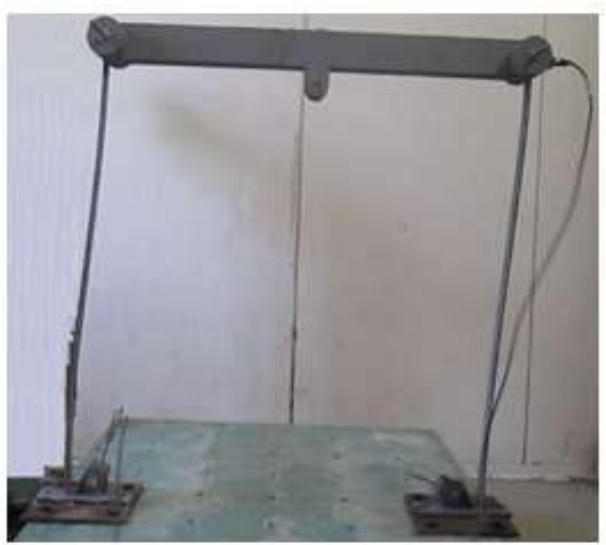

(a)

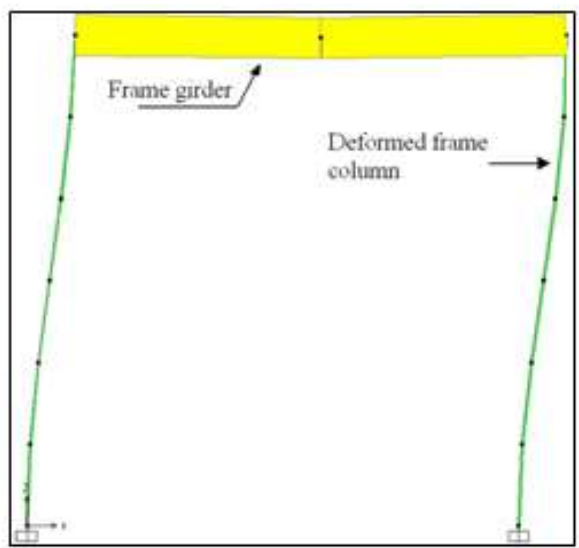

(b)

Fig. 7: (a) Frame deformation shape at lab, (b) Frame deformation shape from FEM 


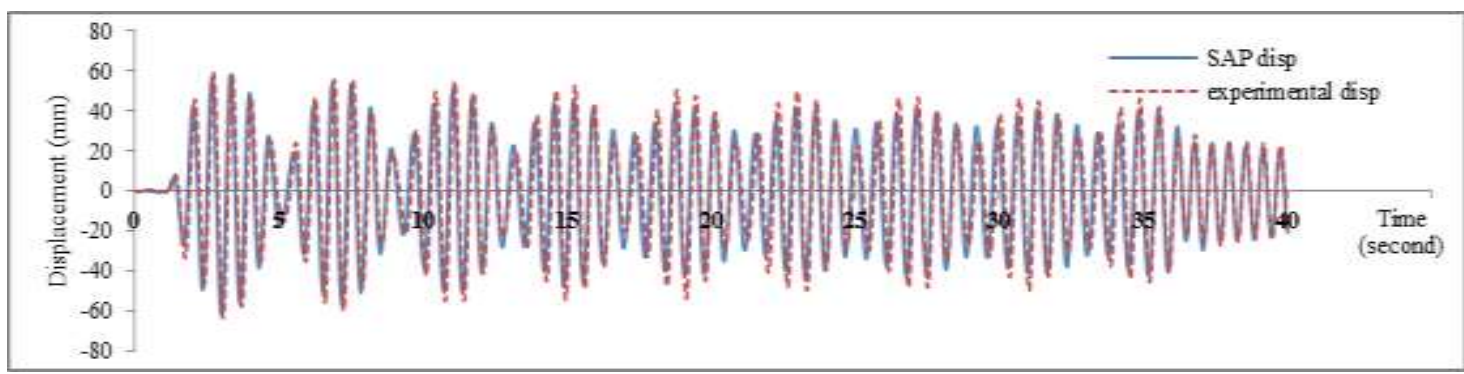

Fig. 8: Comparable Displacements for Test no.3

\section{FE Modeling With Friction Damper}

The same model in section 7.1 is used while adding the damping system as follows. The damper plates are modeled as rigid frame elements; the tie rods are modeled as cable elements. Moment releases are assigned at the locations where hinges are present. A non-linear link with bilinear function is defined based on the hysteresis relation obtained from the experimental work in section 6. It is assigned in damper center.Fig. 9-a presents the configuration of the defined FEM.

The shaking table is excited by constant frequency equal to $2.86 \mathrm{~Hz}$. It is assigned in the software in the presence of defined FDD. Then, the frame response is recorded. A comparison between experimental and numerical model displacement output is illustrated in Fig. 9-b. It clearly shows good agreement. Also, the natural frequency obtained from numerical analysis is $24.27 \mathrm{~Hz}$ against $23.93 \mathrm{~Hz}$ from the experiment. Hence, it can be concluded that the numerical simulation for the FDD using non-linear link with bilinear function is proper.

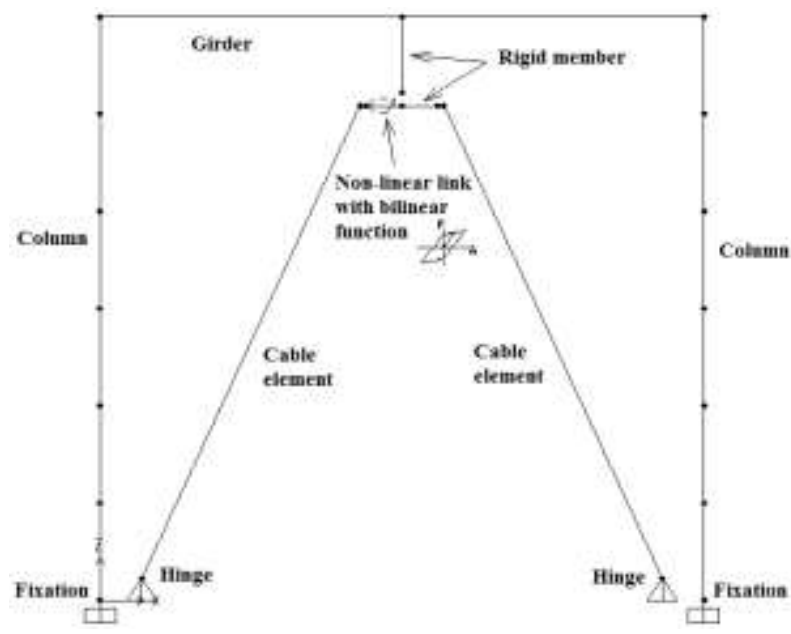

(a)

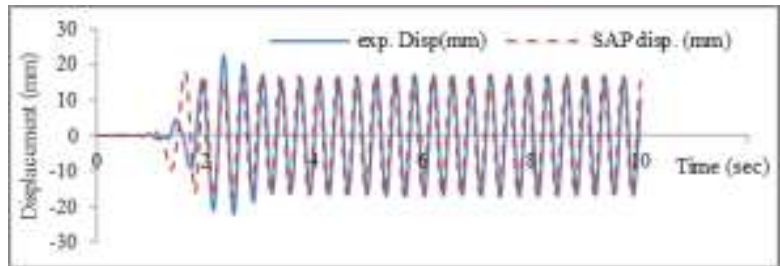

(b)

Fig. 9: (a) Finite element model for frame with damping system,

(b) Comparable response between FEM and experiment

\section{Proposed New Damping System Configuration}

It is proposed to add the pre-stressed rod parallel to the frame columns instead of bracing and fixing the friction hinge to the girder. This configuration is analyzed using the verified FEM model. This proposal gives the advantage of application flexibility in various structures like wide span frames, cantilever frames and braced towers. Fig. 10 shows the proposed configuration and illustrative sketches for various applications, as well as comparable results for the maximum responses for the new configuration and chevron bracing. It is clear that 
the new proposal gives close results to the bracing shape. This paper is a first step for planned future studies that shall be performed to mitigate special structures like offshore platforms and their appurtenances against dynamic loads.

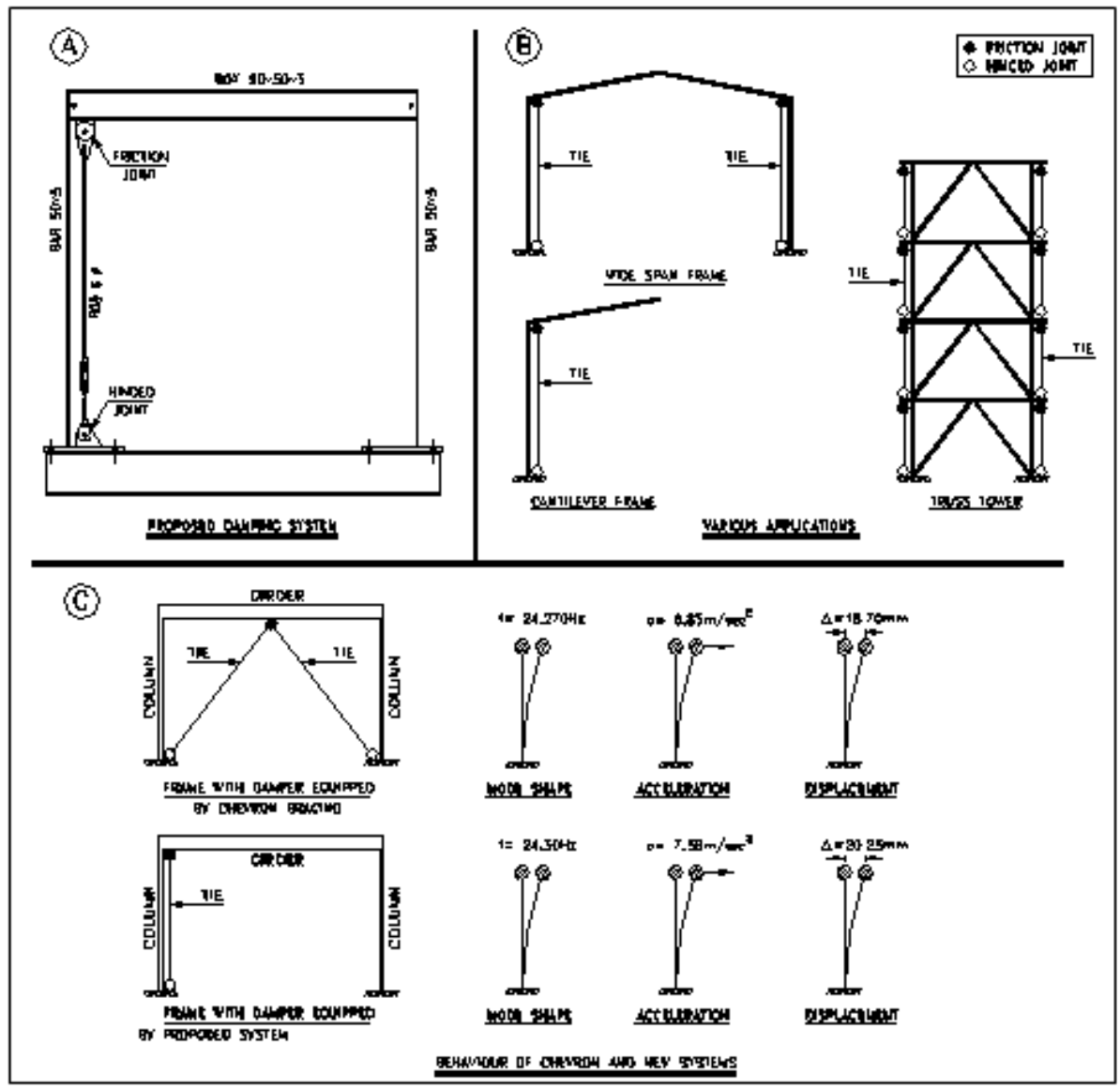

Fig. 10: New proposed damping system and applications

\section{Conclusions And Future Work}

Regarding the performed work in this paper, the following conclusions and planed future work are summarized:

- The FDD can be manufactured and assembled using available materials in the local market in Egypt. The friction pad material is made from Teflon.

- A validation process is performed to experimental measuring devices by testing the frame without the friction damper and comparing the results with the FEM.

- The modeling of the frame using shell elements gives results closer to the experimental values than using frame element modeling. The difference between FEM and experimental results is $13 \%$ for frame elements and $2.6 \%$ for shell elements.

- The hysteresis curve for the damper is extracted. It shows almost stable behavior although the damper is made in a primitive manner.

- The FEM using non-linear link with bilinear function is a proper simulation for the FDD and can be used for numerical studies.

- The proposed new damping configuration provides flexibility in use for various structure types and gives the advantages of ease of erection and maintenance.

- Future work shall focus on using the FDD in rehabilitating and upgrading the offshore platforms and their appurtenances against dynamic loads.

\section{Acknowledgements}

The authors would like to express their deep gratitude to all the laboratory members of National water Research Center in Egypt for their constant effort and support during the preparation of the experimental work. They want to thank too, Damptech Organization Website for the great help of the published papers. 


\section{References}

[1] Pall AS, Marsh C. Response of friction damped braced frames. J StructDiv ASCE; 108:1313-23, 1982.

[2] Aiken, I.D. and Kelly, J.M., Comparative study of four passive energy dissipation systems, Bulletin of New Zealand National Society of Earthquake Engineering, 25, 175, 1992.

[3] Aiken, I.D. et al., Testing of passive energy dissipation systems, EERI Earthquake Spectra, 9, $335,1993$.

[4] Nims, D.K., Richter, P.J., and Bachman, R.E., The use of the energy dissipating restraint for seismic hazard mitigation, Earthquake Spectra, 9, 467, 1993.

[5] Fitzgerald, T.F. et al., Slotted bolted connections in aseismic design for concentrically braced connections, Earthquake Spectra, 5, $383,1994$.

[6] Soong, T.T. and Dargush, G.F., Passive Energy Dissipation System in Structural Engineering, 1st ed., JohnWiley\& Sons, Chichester, England, 1997.

[7] Mualla, I.H., Experimental \& computational evaluation of a new friction damper device. Ph.D. Thesis, Dept. of Structural Engineering and Materials, Technical University of Denmark, 2000.

[8] Mualla, I.H., and B. Belev., Performance of Steel Frames with a New Friction Damper Device Under Earthquake Excitation. J. of Engineering Structures, 2001.

[9] Amir Shirkhani et al., An investigation into the influence of friction damper device on the performance of steel moment frames, AJER, 03, 03, 2014.

[10] Nikam et al., Seismic Energy Dissipation of a Building Using Friction Damper, IJITEE, 03, 10, 2014.

[11] J.G.T. Ribeiro, J.T.P. de Castro and J.L.F. Freire, New Improvements in the Digital Double Integration Filtering Method to Measure Displacements Using Accelerometers. 19 ${ }^{\text {th }}$ International Modal Analysis Conference, P. 538-542, 2001.

[12] Puneet Chugh, et al. Small Scale Modelling and testing of a 3-story steel moment frame building - with/without base isolation project report. CE 623 - Experimental Methods in Structural Engineering, Department of Civil Engineering, Indian Institute of Technology, Kanpur, 2011

[13] Egyptian code for steel buildings design and construction, 2011.

[14] Sivaraos et al., An experimental and numerical investigation of tensile properties of stone wool fiberreinforced polymer composites, Advanced Materials Letters, 06, 10, 2015.

[15] Velmurugan et al., Tensile Test Analysis of Natural Fiber reinforced Composite, IJMIE, 02, 04, 2012.

[16] Rahman et al., Comparison between Experimental and Numerical Studies of Fully Encased Composite Columns, $10,06,2016$. 